\title{
ASSOCIATION BETWEEN THE ANGIOTENSIN II/ANGIOTENSIN (1-7) IMBALANCE AND LEFT VENTRICULAR HYPERTROPHY IN PATIENTS WITH HEART FAILURE \\ ANGIOTENSIN RATIO AND LEFT VENTRICULAR HYPERTROPHY IN HEART FAILURE
}

\author{
A. Nikolov ${ }^{1}$, M. Tzekova ${ }^{2}$, K. Kostov ${ }^{2}$, A. Kostadinovska², S. Blazheva ${ }^{3}$ \\ 'Division of Medicine, Cardiovascular Research Working Group, Institute for Scientific Research, \\ Medical University - Pleven, Bulgaria \\ ${ }^{2}$ Medical University - Pleven, Bulgaria \\ ${ }^{3}$ Department of Clinical Laboratory, Clinical Immunology and Allergology, Medical University - Pleven, Bulgaria
}

\begin{abstract}
Introduction: Angiotensin II (Angll) and angiotensin-(1-7) [Ang-(1-7)] are key components of the renin angiotensin system (RAS). They exhibit counter-regulatory effects in the systemic circulation, as well as in tissues important for cardiovascular regulation. Aim: To investigate the association between the Angll/Ang-(1-7) balance and left ventricular hypertrophy $(\mathrm{LVH})$ in patients with heart failure and mid-range ejection fraction (HFmrEF). Material and methods: 56 patients with HFmrEF were included, with a mean age of $65.62 \pm$ 9.69 years and 22 age- and sex-matched healthy subjects, their mean age $-56.4 \pm 5.53$ years. The patients were divided in two subgroups: subjects with left ventricular hypertrophy $(n=32) ;(H F m r E F+L V H)$ and subjects without left ventricular hypertrophy $(n=24)$; (HFmrEFLVH). Angll and Ang-(1-7) levels were measured with an ELISA kit. Results: Patients with HFmrEF+LVH showed significantly higher levels of Angll: $8.53 \mathrm{pg} / \mathrm{mL}(1.47 \div 13.0)$ than $H F m r E F-L V H-1.33 \mathrm{pg} / \mathrm{mL}(0.47 \div 6.93)$ and healthy controls $-1.53 \mathrm{pg} / \mathrm{mL}(0.27 \div 5.21)$; $(K W=3.48 ; p=0.04)$. There was no significant difference between Ang-(1-7) levels in all patients compared to controls $(p>0.05)$. Angll/Ang-(1-7) ratio was significantly higher in all patients than controls: $3.81(2.03 \div 6.66)$ vs. $1.5(0.93 \div 2.06)(K W=18.68 ; p<0.001)$. Patients with HFmrEF+LVH showed statistically higher Angll/Ang-(1-7) ratio compared with controls (4.7 vs. 1.5). Moreover, subjects with $L V H$ showed the highest Angll/Ang-(1-7) ratio among all particpants in the study. The Angll/Ang-(1-7) ratio correlated with $L V H(r=-0.39 ; p=0.03)$, $\operatorname{DBP}(r=0.25 ; p=0.04), H D L(r=0.33 ; p=0.01), \operatorname{SBP}(r=0.34 ; p=0.01)$. Conclusion: Our study showed an association between Angll/Ang-(1-7) ratio, blood pressure and LVH. The imbalance between Ang-II and Ang-(1-7) could contribute to the mechanisms determining LVH in HFmrEF. Further studies are warranted to clarify whether evaluation of serum Ang-II/ Ang-(1-7) ratio could predict $L V H$ development in patients with HFmrEF.
\end{abstract}

Key words: heart failure, arterial hypertension, angiotensin, left ventricular hypertrophy, renin angiotensin system

Corresponding author: Assoc. Prof. Asparuh Nikolov MD, PhD, Division of Medicine, Cardiovascular Research Working Group, Institute for Scientific Research, Medical University, 1, Sv. Kliment Ohridski Street, Bg - 5800 Pleven, tel. +359 887100672, e-mail: a_nicoloff@yahoo.com

RECEIVED: 13 June 2021; REVISED: 17 July 2021; ACCEPTED: 20 July 2021 


\section{INTRODUCTION}

eft ventricular hypertrophy (LVH) increases heart workload and plays a key role in cardiovascular morbidity and mortality [1]. Besides age, LVH is the most potent predictor of adverse cardiovascular outcomes in the hypertensive population, and is an independent risk factor for coronary heart disease, sudden death, heart failure and stroke [2]. RAS plays an important role in the development of LVH by raising blood pressure (BP) and stimulating proinflammatory and profibrotic effects at a cellular and molecular level $[3,4]$.

An early phase in the development of heart failure is cardiac remodeling, which is thought to be an important aspect of disease progression in heart failure, regardless of cause [5]. The exact mechanisms leading to cardiac remodeling and dysfunction are not completely understood but are thought to arise from a common upstream pathway involving the renin-angiotensin system (RAS) [6].

The classical cascade in the RAS called the ACE/ Ang II/Ang II type 1 receptor axis is known as an inducing factor favoring hypertension and organ damage $[7,8]$. On the other hand, the ACE 2/Ang(1-7)/ Mas receptor arm antagonizes the ACE/Ang II/Ang II type 1 receptor pathway and maintains this fine balance in physiological conditions. Angiotensin II (Angll) and angiotensin-(1-7) [Ang-(1-7)] are key components in the two renin angiotensin system arms mentioned above. They exhibit counter-regulatory effects in the systemic circulation, as well as in tissues important in cardiovascular regulation $[9,10]$. Ang-(1.7) is an endogenous counter-factor of Ang-II. Ang-(1-7) has anti-hypertensive and antiproliferative actions on cardiac myocytes [11] and vascular smooth muscle [12], and is a vasodilator [13]. Indeed, a balance of the two peptides may be required to bypass many cardiovascular processes. Deregulation of the balance between angiotensin II and angiotensin-(1-7) in patients with chronic heart failure might be one of the possible causes for cardiac remodeling.

Heart failure with mid-range ejection fraction (HFm$\mathrm{rEF}$ ) represents mostly a transition phenotype, either to full recovery or to a downhill course of worsening systolic function [14]. Since most studies involve reduced (HFrEF) and preserved ejection fraction (HFpEF) patients, limited data are available on the HFmEF etio-pathogenesis. Pathophysiologic mechanisms of HFmrEF are unknown, but levels of natriuretic peptides lying between that of HFrEF and HFpEF suggest a combination of myocardial stretch and inflammation [15] emphasizing the renin-angiotensin system as a key player in HFmrEF etio-pathogenesis.
AIM

Our objective was to determine whether an association exists between the balance of angiotensin II and angiotensin-(1-7) and left ventricular hypertrophy (LVH) in patients with chronic heart failure and a midrange ejection fraction.

\section{MATERIALS AND METHODS}

\section{Subjects}

The study was approved by the Ethics Committee of Medical University - Pleven. All participants signed informed consent. Study procedures followed all guidelines for ethical standards on human experimentation as well as the Helsinki Declaration of 1975, as revised in 2000. All patients were residing in the surroundings of the Pleven University Hospital. Sera of subjects were collected from September 2016 till June 2018. The study group consisted of 56 patients with HFmrEF, with a mean age $65.62 \pm 9.69$. Forty-one of patients were with hypertension-mediated organ damage (HMOD) and 15 had no such damage. Patients were divided in two subgroups - subjects with mid-range ejection fraction and left ventricular hypertrophy $(n=$ 32 ), mean age $62.5 \pm 12.58$ years (HFmrEF $+L V H)$; subjects with mid-range ejection fraction without left ventricular hypertrophy $(n=24)$, mean age $60.4 \pm 8.4$ years (HFmrEF-LVH) (Table 1). 22 ageand sex-matched healthy subjects with no family history of diabetes, atherosclerosis or hypertension were the control group, with a mean age 56.4 \pm 5.53 years.

Methodically, our study was carried into two parts. Firstly, we measured serum levels of angiotensin II [16]. After that we determined levels of angioten$\sin -(1-7)$ and calculated their ratio. Both markers were measured in sera of patients with HFmrEF and healthy controls.

\section{Hypertension-Mediated Organ Damage (HMOD) Evaluation}

To assess the presence of HMOD patients provided detailed medical history (established cardiovascular or premature CVD, renal, cerebrovascular or ophthalmological damage) and physical examination was done as well.

\section{Blood pressure}

Arterial blood pressure was measured using a standard aneroid sphygmomanometer, to the nearest 2 $\mathrm{mm} \mathrm{Hg}$, at the dominant arm after at least 10-min rest in the supine position. 
Table 1. The clinical data of the patients and healthy controls are shown

\begin{tabular}{|c|c|c|c|}
\hline \multirow[t]{2}{*}{ Clinical data } & \multicolumn{3}{|c|}{ Mean \pm Standard Deviation } \\
\hline & HFmrEF+LVH & HFmrEF-LVH & Controls \\
\hline Age (years) & $62.5 \pm 12.58$ & $60.4 \pm 8.4$ & $56,4 \pm 5,53$ \\
\hline Gender (M/F) & $18 / 14$ & $14 / 10$ & $12 / 10$ \\
\hline Mean duration AH (years) & $9,57 \pm 6,63$ & $7,63 \pm 5,26$ & $\mathrm{~N} / \mathrm{A}$ \\
\hline Mean duration HF (years) & $5,6 \pm 2,9$ & $4,89 \pm 1,60$ & $\mathrm{~N} / \mathrm{A}$ \\
\hline $\mathrm{SBP}(\mathrm{mmHg})$ & $151,35 \pm 16,05$ & $139,11 \pm 18,42$ & $118,26 \pm 13,74$ \\
\hline $\mathrm{DBP}(\mathrm{mmHg})$ & $89,05 \pm 10,32$ & $84,41 \pm 11,73$ & $76,4 \pm 8,4$ \\
\hline $\mathrm{BMl}, \mathrm{kg} / \mathrm{m}^{2}$ & $28,52 \pm 5,99$ & $28,36 \pm 4,96$ & $22,11 \pm 3,27$ \\
\hline Total cholesterol $(\mathrm{mmol} / \mathrm{l})$ & $4,99 \pm 1,30$ & $4,79 \pm 0,83$ & $3,99 \pm 0,65$ \\
\hline $\mathrm{HDL}(\mathrm{mmol} / \mathrm{l})$ & $0,87 \pm 0,29$ & $1,16 \pm 0,20$ & $0,96 \pm 0,20$ \\
\hline $\mathrm{LDL}(\mathrm{mmol} / \mathrm{l})$ & $3,27 \pm 1,17$ & $3,01 \pm 1,07$ & $2,43 \pm 0,64$ \\
\hline Triglycerides (mmol/l) & $1,49 \pm 1,66$ & $1,50 \pm 1,39$ & $1,31 \pm 0,61$ \\
\hline Blood glucose $(\mathrm{mmol} / \mathrm{l})$ & $6,00 \pm 0,52$ & $6,11 \pm 0,83$ & $\mathrm{~N} / \mathrm{A}$ \\
\hline Creatinine $(\mathrm{mcmol} / \mathrm{l})$ & $101,21 \pm 2,87$ & $99,58 \pm 3,69$ & $\mathrm{~N} / \mathrm{A}$ \\
\hline Hypertensive heart damage & $(n=21)$ & - & \\
\hline Hypertensive brain damage & $(n=4)$ & $(n=2)$ & \\
\hline Hypertensive kidney damage & $(n=6)$ & $(n=4)$ & \\
\hline Hypertensive eye damage & $(n=2)$ & $(n=2)$ & \\
\hline Smoking & 21 & 16 & 8 \\
\hline Number & 32 & 24 & 22 \\
\hline
\end{tabular}

BMI - Body mass index; DBP - Diastolic blood pressure; HDL - High density lipoprotein cholesterol; HFmrEF+LVH - mid-range ejection fraction and left ventricular hypertrophy; HFmrEF-LVH - mid-range ejection fraction without left ventricular hypertrophy; LDL - Low density lipoprotein cholesterol; SBP - Systolic blood pressure

\section{Electrocardiography}

Electrocardiography was performed for LVH assessment and the Sokolow-Lyon index, Cornell voltage duration product or Cornell voltage were estimated [17].

\section{Echocardiography}

Echocardiography was performed on a General Electric device (Vivid S5) with a 4-MHz transducer. All measurements were obtained according to the European Association of Cardiovascular Imaging (EAC-
$\mathrm{VI}$ ) and the American Society of Echocardiography (ASE) criteria for Cardiac Chamber Quantification by Echocardiography [18]: echocardiographic LVH [if: LV mass weight > $224 \mathrm{~g}$ (men); > $162 \mathrm{~g}$ (women); LV mass index: men $>50 \mathrm{~g} / \mathrm{m}^{2}$; women $>47 \mathrm{~g} / \mathrm{m}^{2}$ (height in $\mathrm{m}$ )] (Table 2).

\section{Laboratory tests}

1. Serum uric acid and blood glucose were measured. Total cholesterol, triglycerides, HDL-cholesterol were measured by an enzyme assay (Boehringer

Table 3. Serum levels of Angiotensin II in patients with heart failure with mid-range ejection fraction and healthy controls according to presence of LVH

\begin{tabular}{|l|c|c|l|c|c|}
\hline & $\begin{array}{c}\text { Angiotensin II (ng/ml) } \\
\mathbf{M} \div(\mathbf{Q} 1 \text { toQ3) }\end{array}$ & $\begin{array}{c}\text { Compari- } \\
\text { son with }\end{array}$ & & $\begin{array}{c}\text { Angiotensin II (ng/ml) } \\
\mathbf{M} \div(\mathbf{Q} 1 \text { toQ3) }\end{array}$ & $\begin{array}{c}\text { Comparison } \\
\text { with }\end{array}$ \\
\hline Patients & $\begin{array}{c}\text { s,95 } \\
(1,68 \div 13,92)\end{array}$ & $\begin{array}{c}\text { Controls } \\
p=0,03\end{array}$ & HFmrEF+LVH & $\begin{array}{c}8,53 \\
(1,47 \div 13,0)\end{array}$ & HFmrEF-LVH \\
& 1,53 & Patients & HFmrEF-LVH & 1,04 \\
\hline Controls & $(0,58 \div 7,14)$ & $p=0,03$ & & $(0,47 \div 6,93)$ & HFmrEF+LVH \\
& & & $p=0,04$ \\
\hline
\end{tabular}


Mannheim, Mannheim, Germany). LDL was calculated using the Friedewald formula.

2. Serum creatinine levels were measured and moderate CKD with eGFR $>30-59 \mathrm{~mL} / \mathrm{min} / 1.73 \mathrm{~m}^{2}$ (BSA) or severe CKD with GFR $<30 \mathrm{~mL} / \mathrm{min} / 1.73 \mathrm{~m}^{2}$ were documented.

If evidence of HMOD was found, the patient was further consulted by a specialist (cardiologist, nephrologist, neurologist, ophthalmologist).

\section{ELISA}

Enzyme-linked immunosorbent assay (ELISA) was used for measuring Angll and Ang-(1-7) levels.

- Angiotensin II levels were measured in serum samples using the ELISA kit by ALPCO Diagnostics (Salem, MA, USA, 74-ANGHU-E01) according to the manufacturer's instructions.

- Angiotensin-(1-7) levels were measured in serum samples using (IW-NBP2-69) Human Angiotensin 1-7 ELISA Kit- Novus Biologicals according to the manufacturer's instructions.

\section{Statistical analyses}

The research data were processed using EXCEL (Microsoft Corporation, Redmond, WA) and STATGRAPHICS plus (Manugistics, Rockville, MD) for WINDOWS. All results were presented in tables, graphs, numerical values (mean $\pm S D$, share indicators and correlations). The level of significance was determined as $p<0.05$. K-W (Kruskal-Wallis)-test was performed in cases with a distribution different from normal. Median (M) was used in the K-W test, together with first and third quartile Q1 and Q3; (twenty-fifth and seventy-fifth percentile P25 and 75P). The Pearson test was used for estimating correlations.

\section{RESULTS}

Angll serum levels were significantly higher in patients compared to controls: $8.95 \mathrm{pg} / \mathrm{mL}(1.68 \div 13.92)$ vs. $1.53 \mathrm{pg} / \mathrm{mL}(0.58 \div 7.14)(p=0.03)$. Patients with HFmrEF+LVH showed significantly higher levels of Angll: $8.53 \mathrm{pg} / \mathrm{mL}(1.47 \div 13.0)$ than HFmrEF-LVH 1.33 $\mathrm{pg} / \mathrm{mL}(0.47 \div 6.93)$ and healthy controls $1.53 \mathrm{pg} / \mathrm{mL}$ $(0.27 \div 5.21) ;(\mathrm{KW}=3.48 ; \mathrm{p}=0.04)$ (Table 3$)$. There was no significant difference between Ang-(1-7) levels in the patients compared to controls $(p>0.05)$ (Table 4). Angll/Ang-(1-7) ratio was statistically significantly higher in all patients than controls: $3.81(2.03 \div 6.66)$ vs. $1.5(0.93 \div 2.06)(\mathrm{KW}=18.68 ; \mathrm{p}<0.001)$ (Figure 1$)$. Patients with $\mathrm{HFmrEF}+\mathrm{LVH}$ showed statistically higher Angll/Ang-(1-7) ratio compared with controls (4.7 vs. 1.5). In addition, subjects with left ventricular hypertrophy showed the highest Angll/Ang-(1-7) ratio from all participants. The Angll/Ang-(1-7) ratio correlated with $\mathrm{LVH}(r=-0.39 ; p=0.03), \mathrm{DBP}(r=0.25 ; p=0.04), \mathrm{HDL}$ $(r=0.33 ; p=0.01), \operatorname{SBP}(r=0.34 ; p=0.01)$.

Angll - angiotensin II, Ang-(1-7) - angiotensin-(1-7), $H F m r E F+L V H-$ mid-range ejection fraction and left ventricular hypertrophy, HFmrEF-LVH - mid-range ejection fraction without left ventricular hypertrophy

Table 3. Serum levels of Angiotensin- (1-7) in patients with heart failure with mid-range ejection fraction and healthy controls according to presence of LVH

\begin{tabular}{|c|c|c|c|c|c|}
\hline & $\begin{array}{c}\text { Angiotensin 1-7 (ng/ml) } \\
\text { M } \div \text { (Q1toQ3) }\end{array}$ & Comparison with & & $\begin{array}{c}\text { Angiotensin 1-7 (ng/ml) } \\
\text { M } \div(\mathrm{Q} 1 \text { toQ3) }\end{array}$ & Comparison with \\
\hline Patients & 52,1 & Controls & HFmrEF+LVH & $\begin{array}{c}45,2 \\
(31,0 \div 68,0)\end{array}$ & $\begin{array}{c}\text { HFmrEF-LVH } \\
\mathrm{P}>0,05\end{array}$ \\
\hline Controls & $(32,8 \div 85,2)$ & $\mathrm{P}>0,05$ & & $\begin{array}{c}62,8 \\
(41,3 \div 90,9)\end{array}$ & $\begin{array}{c}\mathrm{HFmrEF}+\mathrm{LVH} \\
\mathrm{P}>0,05\end{array}$ \\
\hline
\end{tabular}

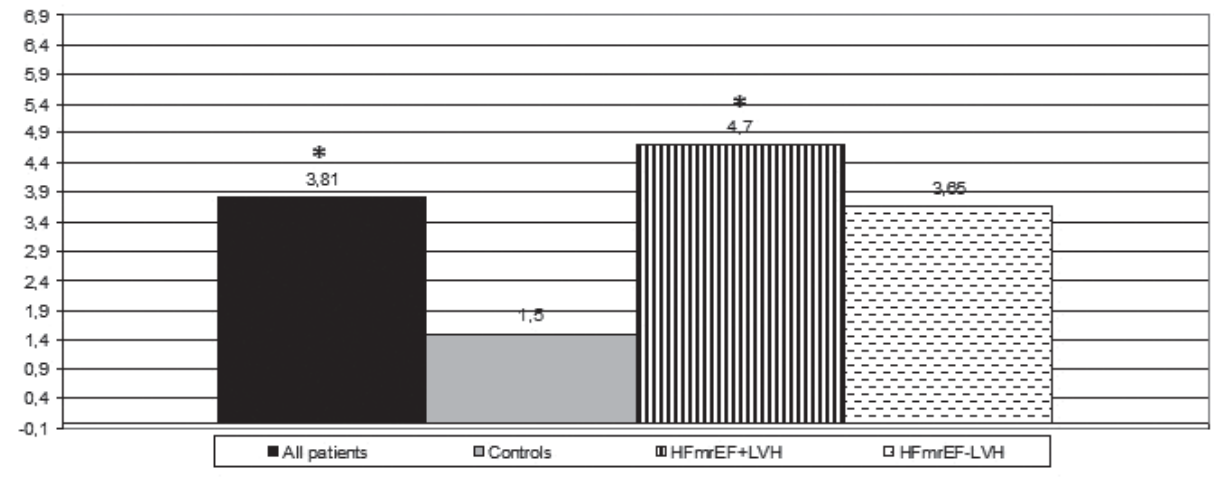

Fig. 1. Angiotensin II/Angiotensin-(1-7) serum ratio in all participants in the current study Angll/Ang-(1-7) ratio was significantly higher in patients than controls 3.81 vs. 1.5 ( $p<$ $0.001)$. Angll/Ang-(1-7) ratio was significantly higher in patients with $\mathrm{HFmrEF}+\mathrm{LVH}$ than in healthy controls 4.70 vs. 1.5 $(p<0.001)$ 


\section{DISCUSSION}

Circulating angiotensin II has been reported to be chronically increased when coming from either endogenous or exogenous sources [19]. Angiotensin-(1-7) is known to exert anti-hypertensive, organprotective and anti-fibrotic effects. Several studies reported that both angiotensin-converting enzyme (ACE2) and Ang-(1-7) had cardio-protective effects in experimental animals as well as in cultured cardiac fibroblasts and myocytes [20-24]. Hao et al. (2013) further found that plasma Ang-(1-7) level was independently associated with the amelioration of cardiac damage and function after reperfusion therapy in patients with acute myocardial infarction [25].

In another study $\mathrm{Hao}$ et al. (2013) evaluated the association of plasma Ang-(1-7) level and left ventricular function in patients with type 2 diabetes mellitus [26]. The authors measured the left ventricular ejection fraction (EF), the ratio of early to late left ventricular filling velocity $(E / A)$ and the ratio of early diastolic mitral inflow to annular velocity (E/Ea) by ultrasonography in 110 patients with type 2 diabetes mellitus with a duration longer than 5 years. They concluded that plasma Ang-(1-7) level was independently associated with left ventricular function in patients with type 2 diabetes mellitus and might be used as a biomarker when assessing cardiac function in such patients.

Hisatake et al. (2017) reported that acute decompensated heart failure patients had a significantly higher serum ACE2 concentration and a significantly lower serum Ang-(1-7) concentration when compared with healthy volunteers [27]. In 2020 Hisatake et al. elucidated the role of ACE2/angiotensin (Ang)-(1-7)/ Mas receptor axis in acute decompensated heart failure with reduced ejection fraction. The authors investigated serial changes in serum ACE2 and Ang-(1-7) concentrations after optimal therapy (OT) in acute heart failure (AHF) patients with reduced ejection fraction (EF). ACE2 and Ang-(1-7) concentrations were measured in $68 \mathrm{AHF}$ patients with reduced EF immediately after admission and 1 and 3 months after optimal therapy. These parameters were compared with the healthy individuals at three time points. ACE2 concentration was equal between AHF patients and the healthy individuals at 1 and 3 months after study start, and Ang-(1-7) concentration was equal at 3 months. Although this particular study did not elucidate the mechanisms of the changes in ACE2 and Ang-(1-7) concentrations, it showed that the serum ACE2 concentration declined and the Ang(1-7) concentration increased by optimal therapy in compensated heart failure cases, and as a result, both concentrations were similar to those of the healthy individuals" [28].

Wang K et al. (2020) hypothesized that the dynamic state of the renin-angiotensin system protective arm could influence long-term outcomes in patients with heart failure. The authors examined plasma Ang-(17)/Ang-II ratio and long-term outcomes in patients with heart failure. One hundred ten patients with heart failure from outpatient clinics and the emergency department were followed up for median 5.1 years. Researchers identified elevated Ang-1-7/Angll ratio, as an independent and incremental predictor of beneficial outcomes, higher survival rate, and decreased hospitalization duration. These findings provide evidence that elevated Angiotensin-(1-7)/Angiotensin II ratio may predict favorable outcomes in patients with heart failure [29].

Normally, the 'traditional' ACE/Ang II/Ang type 1 receptor pathway appears to be balanced by the vasodepressor arm of the RAS [ACE 2/Ang-(1-7)/Mas receptor] [30, 31, 32]. Interestingly, the balance between circulating Angll and Ang-(1-7) in patients with chronic heart failure has not been fully elucidated yet. There have been almost no reports to date that measured serum angiotensin II and angiotensin-(1-7) levels in patients with chronic heart failure with midrange ejection fraction. Studies have involved patients with acute heart failure, hypertension, diabetes mellitus, but none of the above commented investigations focused on patients with chronic heart failure with mid-range ejection fraction.

All patients in the current study had compensated chronic heart failure treated with optimal therapy, according to the appropriate guidelines. This can be one of the possible reasons for lack of statistical difference between Angll/Ang-(1-7) ratios in HFmrEF+LVH compared with HFmrEF-LVH patients. Of note, Hisatake et al. (2020) showed the increased serum ACE2 concentration gradually decreased to normal value, and the decreased serum Ang-(1-7) concentration gradually increased to normal value, in patients with acute decompensated heart failure with reduced LVEF, who were compensated after optimal medical therapy based on guidelines [28].

The major findings in our study were: disrupted balance between angiotensin II and angiotensin-(1-7) and relationship between serum Angll/Ang-(1-7) ratio and LVH in chronic heart failure with mid-range ejection fraction. Hereby, we might suggest that altered stability between the two main RAS pathways might play an important role in the development of left ventricular hypertrophy. To the best of our knowledge, our study has provided for the first time data about 
the relationship between serum Angll and Ang-(1-7) in chronic heart failure with mid-range ejection fraction. It should be kept in mind that we assessed just the levels of circulating RAS components and their ratios, therefore the role of local RAS and evaluation of these components' activity cannot be commented upon. Although we did not establish a direct causal link among medical events, we hereby reported an association between the imbalance of angiotensin II and angiotensin-(1-7) and left ventricular hypertrophy. Probably more sensitive methods would identify that link such as Western blot, cardiovascular magnetic resonance or immunohistochemistry/immunocytochemistry with tissue samples analysis.

Our study revealed that despite optimal therapy, an altered balance between the vasoconstrictor and vasodepressor arms [Ang II/Ang (1-7)] of the RAS imight be observed in patients with chronic heart failure with mid-range ejection fraction. We suggested that different additional factors like low physical activity, sympathetic nerve system activation, a high salt intake or alcohol consumption might also contribute to disturbing the equilibrium between the two RAS pathways, thus favoring a vasoconstrictor and proinflammatory state. The net effect of RAS imbalance might contribute to development and progression of $\mathrm{LVH}$, but the exact mechanisms are unclear yet. The small sample size and the cross-sectional design were limitations of the current study. Larger and longitudinal studies are needed to clarify whether determination of serum Ang-II/Ang-(1-7) ratio could predict LVH development in patients with HFmrEF.

\section{CONCLUSION}

Our findings showed an association between Angll/ Ang-(1-7) ratio, blood pressure and LVH. The imbalance between angiotensin II and angiotensin-(1-7) could be a factor contributing to the mechanisms of LVH development in HFmrEF.

Disclosure summary: The authors have nothing to disclose.

Acknowledgements: Funding: This research was supported by the Centre of Scientific Research of Medical University - Pleven, Bulgaria

\section{REFERENCES}

1. Levy D, Garrison RJ, Savage DD, et al. Prognostic implications of echocardiographically determined left ventricular mass in the Framingham Heart Study. N Engl J Med. 1990; 322: 1561-1566.

2. Gradman AH, Alfayoumi F. From left ventricular hypertrophy to congestive heart failure: management of hypertensive heart disease. Prog Cardiovasc Dis. 2006; 48(5): 326-41. doi: 10.1016/j.pcad.2006.02.001. PMID: 16627048.

3. Dahlöf B. Left ventricular hypertrophy and angiotensin II antagonists. Am J Hypertens. 2001; 14(2): 174-82. doi: 10.1016/ s0895-7061(00)01257-7. PMID: 11243310.

4. Cowan BR, Young AA. Left ventricular hypertrophy and reninangiotensin system blockade. Curr Hypertens Rep. 2009; 11(3): 167-172. doi:10.1007/s11906-009-0030-9

5. Shah AM, Hung CL, Shin SH, et al. Cardiac structure and function, remodeling, and clinical outcomes among patients with diabetes after myocardial infarction complicated by left ventricular systolic dysfunction, heart failure, or both. Am Heart J. 2011; 162: 685-691.

6. Kuenzli A, Bucher HC, Anand I, et al. Metaanalysis of combined therapy with angiotensin receptor antagonists versus ACE inhibitors alone in patients with heart failure. PLoS One 2010; 5: e9946.

7. The Consensus Trial Study Group. Effects of enalapril on mortality in severe congestive heart failure. Results of the Cooperative North Scandinavian Enalapril Survival Study (CONSENSUS). N. Engl. J. Med. 1987; 316: 1429-1435. https://doi. org/10.1056/NEJM198706043162301

8. The SOLVD Investigators. Effect of enalapril on survival in patients with reduced left ventricular ejection fractions and congestive heart failure. N. Engl. J. Med. 1991; 325: 293-302. https://doi.org/10.1056/NEJM199108013250501

9. Heusch G, Libby P, Gersh B. Cardiovascular remodeling in coronary artery disease and heart failure. Lancet. 2014; 383: 1933-1943.

10. Mehta PK, Griendling KK. Angiotensin II cell signaling: physiological and pathological effects in the cardiovascular system. Am J Physiol Cell Physiol. 2007; 292: 82-97.

11. Tallant EA, Ferrario CM, Gallagher PE. Angiotensin-(1-7) inhibits growth of cardiac myocytes through activation of the mas receptor. Am J Physiol Heart Circ Physiol. 2005; 289: H1560-H1566.

12. Strawn WB, Ferrario CM, Tallant EA. Angiotensin-(1-7) reduces smooth muscle growth after vascular injury. Hypertension 1999; 33: 207-211.

13. Ferrario CM, Trask AJ, Jessup JA. Advances in biochemical and functional roles of angiotensin-converting enzyme 2 and angiotensin-(1-7) in regulation of cardiovascular function. Am J Physiol Heart Circ Physiol. 2005; 289: H2281-H2290.

14. Margonato D, Mazzetti S, De Maria R, et al. Heart Failure With Mid-Range Or Recovered Ejection Fraction: Differential Determinants Of Transition. CFR. 2020; 6: e28.

15. Albakri A. Heart failure with mid-range ejection fraction A review of clinical status and meta-analysis of clinical management methods. Trends in Research. 2018; 1(4): 1-2.

16. Nikolov A, Tzekova M, Kostov K, Blazhev A. Association between serum matrix metalloproteinase-12/angiotensin II profile and left ventricular hypertrophy in patients with heart failure. Arch. Balkan Medical Union. 2020; 55(2): 233-242.

17. Lehtonen AO, Puukka P, Varis J, et al. Prevalence and prognosis of ECG abnormalities in normotensive and hypertensive individuals. J Hypertens. 2016; 34: 959-966.

18. Marwick TH, Gillebert TC, Aurigemma G et al. Recommendations on the use of echocardiography in adult hypertension: a report from the European Association of Cardiovascular Imaging (EACVI) and the American Society of Echocardiography (ASE). Eur Heart J Cardiovasc Imaging. 2015; 16: 577-605.

19. Weber K. Extracellular Matrix Remodeling in Heart Failure. A Role for De Novo Angiotensin II Generation. Circulation. 1997; 96(11): 4065-4082. 
20. Dong B, Yu QT, Dai HY, et al. Angiotensin-converting enzyme-2 overexpression improves left ventricular remodeling and function in a rat model of diabetic cardiomyopathy. J Am Coll Cardiol. 2012; 59: 739-747.

21. Feng $Y$, Hans $C$, Mcllwain E, et al. Angiotensin-converting enzyme 2 over-expression in the central nervous system reduces angiotensin-II-mediated cardiac hypertrophy. PLoS One 2012; 7: e48910.

22. Pei Z, Meng R, Li G, et al. Angiotensin-(1-7) ameliorates myocardial remodeling and interstitial fibrosis in spontaneous hypertension: role of MMPs/TIMPs. Toxicol Lett 2010; 199: 173-181.

23. Johnson JA, West J, Maynard KB, Hemnes AR. ACE2 improves right ventricular function in a pressure overload model. 2011; PLoS One 6: e20828.

24. Flores-Muñoz M, Godinho BM, Almalik A, Nicklin SA. Adenoviral delivery of angiotensin-(1-7) or angiotensin-(1-9) inhibits cardiomyocyte hypertrophy via the mas or angiotensin type 2 receptor. 2012; PLoS One 7: e45564.

25. Hao PP, Liu YP, Hou GH, et al. Usefulness of angiotensin-(1-7) to predict myocardial salvage after percutaneous coronary intervention in patients with acute myocardial infarction. Int J Cardiol. 2013; 168(1): 614-6. doi: 10.1016/j. ijcard.2013.01.206.

26. Hao PP, Chen YG, Liu YP. Association of plasma angiotensin-(1-7) level and left ventricular function in patients with type
2 diabetes mellitus. 2013; PLoS One 8(5): e62788. https:// doi:10.1371/journal.pone.0062788

27. Hisatake S, Kiuchi S, Kabuki T, et al. Serum angiotensinconverting enzyme 2 concentration and angiotensin-(1-7) concentration in patients with acute heart failure patients requiring emergency hospitalization. Heart Vessels. 2017; 32: 303-308. https://doi.org/10.1007/s00380-016-0877-z

28. Hisatake $\mathrm{S}$, Kiuchi $\mathrm{S}$, Kabuki $\mathrm{T}$. The serum angiotensinconverting enzyme 2 and angiotensin-(1-7) concentrations after optimal therapy for acute decompensated heart failure with reduced ejection fraction. Biosci Rep. 2020; 40(6): BSR20192701. doi:10.1042/BSR20192701

29. Wang K, Basu R, Poglitsch M, et al. Elevated Angiotensin 1-7/ Angiotensin II Ratio Predicts Favorable Outcomes in Patients With Heart Failure. Circ Heart Fail. 2020; 13(7): e006939. doi: 10.1161/CIRCHEARTFAILURE.120.006939.

30. Santos RA, Ferreira AJ, Verano-Braga T, Bader M. Angiotensin-converting enzyme 2, angiotensin-(1-7) and Mas: new players of the renin-angiotensin system. J Endocrinol. 2013; 216: R1-R17.

31. Jones ES, Vinh A, McCarthy CA, et al. AT 2 receptors: functional relevance in cardiovascular disease. Pharmacol Ther. 2008; 120: 292-316.

32. Ribeiro-Oliveira A, Nogueira AI, Pereira RM, et al. The reninangiotensin system and diabetes: an update. Vasc Health Risk Manag. 2008; 4(4): 787e803. 